Introduction

\author{
Paulo A.L.D. Nunes, Lisa Emelia Svensson and \\ Anil Markandya
}

I saw for the first time the earth's shape. I could easily see the shores of continents, islands, great rivers, folds of the terrain, large bodies of water. The horizon is dark blue, smoothly turning to black ... the feelings which filled me I can express with one word - joy.

Yuri A. Gagarin, Sputnik astronaut and first man in space

How inappropriate to call this planet Earth when it is quite clearly Ocean.

Arthur C. Clarke, writer

\title{
SETTING THE SCENE
}

Oceans are a critical part of Earth's life-support system and vital for the well-being of humanity. Once thought to be never-ending, ocean resources are showing serious signs of decline on a global scale. Today there is little doubt that the world faces great challenges to sustain the health of its oceans and, as a consequence, the usage of marine resources. Adverse changes are taking place at an extraordinary rate, relative to those seen over millions of years. Over the past 50 years the world's oceans have been subject to greater human pressure than at any time in recorded history. These pressures have taken a considerable toll on the resilience and productivity of the marine environment. Collapsing fisheries, vanishing habitat, and global pollution are threatening the marine ecosystem goods and services on which humanity depends for future generations.

\section{Negative Trends}

The rising demand for ocean resources in combination with technological advances, climate change, biodiversity and habitat loss has put ocean health at a tremendous risk. Increasing atmospheric carbon dioxide $\left(\mathrm{CO}_{2}\right)$ concentrations have resulted in ocean acidification rising by 26 per cent, and oxygen levels in the oceans decreasing as a result of ocean warming and other factors such as coastal eutrophication. This adds to the already negative trends, such as unsustainable fishing practice much of which is illegal, unreported and unregulated, marine pollution, and degradation of coral reefs, mangrove forests and related ecosystems that are a primary source of food and income for communities. They also provide protection from storms, tsunamis and coastal erosion, in addition to aesthetic and cultural dimensions. The oceans and marine biodiversity are increasingly negatively affected by marine pollution of many kinds, particular plastic, but also persistent organic pollutants, heavy metals and nitrogen-based compounds from marine and land-based sources. The emergence of microplastics entering marine food chains and the potential risk for the environment and human health has just in recent years been addressed. 


\section{Handbook on the economics and management of sustainable oceans}

\section{Lack of Governance}

The weak (or lack of) ocean governance has resulted in a patchwork, sectorial and incomplete structure of control. One of the fundamental barriers to restoring ocean health is the lack of coherent global governance, including weak compliance and lack of enforcement. Although we are starting to see national and regional maritime spatial planning and integrated coastal management, crucial work still lies ahead on strengthening regional governance and enhancing cooperation and coordination among international organizations. Furthermore, support for an ecosystem-based approach to the conservation and sustainable use of oceans and ocean resources is fundamental. Simultaneously, human activities on land and in the oceans are causing rapid deterioration in the marine environment. It is crucial to address successfully the link between land and sea activities. Effective best practices from the United Nations Environment Programme's (UNEP's) Global Programme of Action for the Protection of the Marine Environment from landbased activities (GPA) are described in Chapter 27, and give an overview of how best to target urgent topics such as marine litter, nutrients and wastewater.

\section{Urgent Action Needed}

We must reverse the negative trends to ensure that future generations can benefit from the oceans' beauty and wealth. While there are many successful interventions and reasons for hope, urgent and concerted action on a global scale needs to be ramped up to ensure necessary progress in improving the health of oceans and ocean services to offset the rapid decline. Ocean resources, if managed sustainably, should be a major contributor to securing food safety and energy needs. The food security of some of the world's poorest populations is threatened by the current degraded state of global fisheries, and the situation is expected to get worse. Several authors have stressed the need to consider the role fish can play in contributing to securing food and nutritional security for the world's growing population. Chapter 11, which discusses the 'Impact of high seas closure on food security in low-income fish-dependent countries', notes that if they manage ocean resources well, the least developing countries (LDCs) may stand to benefit the most from high seas closure in terms of having the largest proportion of countries that would experience catch gains. It is therefore crucial to develop capacity-building for ocean governance (spatial planning) to all countries but especially LDCs and small island developing states. Poverty and hunger can be reduced greatly if marine resources are to be managed.

\section{UN Charter - The Lack of Institutional Governance}

Since its formation, the United Nations (UN) has witnessed much change in terms of the legal status of oceans, the technology available to obtain marine scientific knowledge and the sort of data required. For example, private individuals and companies are now able to access the deepest parts of the ocean, which was something that only government-backed projects could manage in 1960. With the emergence of successive iterations of the Law of the Sea, including a number of conventions during the early Cold War era, interest in national jurisdiction of the oceans began to grow alongside the need for agreed international protocols and standards. Consequently, the need for intergovernmental coopera- 
tion became more apparent but the problem is complex and solutions fragmented in the case of oceans. To combat climate change there is one main convention. When it comes to regulating the oceans there are over 567 agreements relating to their governance. A global ocean governance framework is therefore crucial. There is a plethora of ocean bodies with a range of ocean-related remits. Combined with changes in the jurisdiction of the seas, these developments have the potential to confuse and reduce the distinction between national, regional and international ocean governance. There are the high seas, the Exclusive Economic Zones and local waters. To harmonize these there is a need for an integrated approach to the governance of oceans, with appropriate management tools in place, for example, the Marine Spatial Planning. Regional conventions such as Barcelona, the Convention for the Protection of the Marine Environment of the North-East Atlantic (OSPAR) and the Baltic Marine Environment Protection Commission (HELCOM), which can ensure multi-stakeholder involvement and provide a regional forum for identifying common issues, priorities and actions. At the same time a crucial task is to implement the work done in the regional conventions. Valdés points out in Chapter 18 that the UN architecture for ocean science knowledge and governance has four essential pillars with a special and necessary role for sustainable governance. The first pillar is the intergovernmental organizations such as the UN; the second is the international law for the management of natural environment; the third is implementation of scientific programmes for sustainability; and the last is the importance of the science-policy interface. For any sustainable management of a natural resource such as the oceans, there must be the foundation for policy decisions. Therefore science must be viewed as an integrated part of ocean governance - through the so called science-policy interface. The newly adopted UN Sustainable Development Goals (SDGs) will also provide a foundation for future integrated global ocean governance. Sustainable Development Goal 14 has prepared the ground for momentum in the ocean space. We need to use the knowledge we have to act, but also encourage the development of new knowledge on marine resources, mapping, assessment and evaluation, and ensure all countries have access.

\section{Governance}

The world's oceans and coastal ecosystems provide critical services - food security, livelihoods and coastal protection - for billions of people. Because of their transboundary nature, these multi-country systems represent international public goods, making ocean governance particularly complex. The governance approach must ensure integration in key areas, such as sustainable aquaculture, fisheries reform, combating marine pollution, conserving critical habitat and species, and engaging in integrated ecosystem-based management. Through this we can provide attractive economic development opportunities while also improving sustainable management practices and governance in vulnerable coastal communities. Multidimensional partnerships focused on achieving economic and socio-ecological sustainability are essential for lasting success. This book recognizes that problems and solutions vary across the world's oceans; and consequently a 'one size fits all' approach is unlikely to work. It is important to have a system that can adapt to rapid technological developments and engage with science-policy mechanisms. We need innovative science to meet societal need. The science to policy knowledge exchange agenda must be addressed. 


\section{Agenda 2030 - Opportunities for the Oceans}

The significant contribution of oceans to the three dimensions of sustainable development (economic, social and environmental) was not given the attention it deserved in the Millennium Development Goals. With the SDGs, however, a tremendous opportunity has been raised through the inclusion of goal 14 in the SDG framework (SDG14). This goal is recognition of the vital importance of healthy oceans to sustaining life and livelihoods on Earth. The stand-alone SDG on ocean sustainability has the possibility to give an injection to effective integrated global governance. At the same time SDG14 is very much connected to other related SDGs, such as poverty reduction (SDG1), food security (SDG2), health and well-being (SDG3), clean water (SDG6), affordable and clean energy (SDG7), inclusive and sustainable economic growth (SDG 8), sustainable consumption and production (SDG 12), climate action (SDG13) and terrestrial biodiversity (SDG15), and on public-private partnership (SDG17). It is not just a coastal state or small island developing state issue - we all stand to benefit from healthy, productive and resilient oceans and seas. The need for a dedicated high-level global platform to drive progress and promote the implementation of SDG14 is clear. As Valdés points out in Chapter 18, the advantages of consolidating ocean issues into one potentially high-profile SDG will foster increased policy coherence by referencing other existing goals, targets and indicators, and communicating a sustainability narrative with the potential to reach a broader political audience beyond the ocean community. Education, capacity-building and knowledgetransfer on how to use, restore and develop ocean and marine resources will be crucial in the future, particularly the support to developing countries including small developing island states and least developed states. Furthermore, the ocean goal SDG14 has the potential to build the momentum for a fast-track path in restoring ocean health by 2030 . Communication and sharing best practice will be needed to address ocean literacy, which would foster the next generation of ocean leaders and ensure that future generations can benefit from ocean wealth. Global leadership on oceans is crucial. At the same time lack of progress and coordination has encouraged further actions outside the traditional UN bodies. The US Secretary of State has taken an initiative for a high-level conference 'Our ocean', held for first time in Washington 2014, followed by Chile 2015, Washington 2016 and Europe 2017. The overarching objective of the conference has been to inspire and empower a new generation of leaders, entrepreneurs, scientists and civil society to identify solutions and commit to actions to protect and conserve our oceans and their resources.

\section{STRUCTURE AND OVERVIEW OF THE HANDBOOK}

This volume addresses the new concepts and innovative approaches in the economics and management of sustainable oceans and provides policy-relevant recommendations for better governance of the oceans. Part I of the Handbook, on methods, addresses the emerging multidisciplinary methods for valuation of marine and coastal ecosystem services.

Chapter 1 focuses on the implementation of the Marine Strategy Framework Directive and the Water Framework Directive, which aims to achieve sustainable management and good environmental status of the European Union's waters. In particular, it presents an integrated socio-economic assessment tool for assessing the implementation of multi-use 
offshore platforms as a means to accomplish the efficient use of marine space. The proposed objective is to develop a floating modular multi-use platform system for use in deep waters, designed to be flexible enough so as to not be limited in geographic scope and to facilitate synergies between offshore industries and efficient resource use by combining, for example, offshore wind with offshore aquaculture, to boost offshore renewable energy use as well as to support recreational activities. This innovative tool helps policy-makers to select the most appropriate platform design, taking into account technological feasibility, legal feasibility, energy production potential, the environmental impact involved, its financial feasibility and the economic and social impact of the designed platform along with its accompanying activities. These elements are integrated in the assessment tool that consists of four parts. The first corresponds to the technical and legal feasibility of the platforms, based on identified legal and technical constraints. The second corresponds to the environmental impact assessment, taking into account environmental effects produced by the implementation of the platforms. The third includes economic and financial data, as well as monetized environmental effects estimated using methods proposed by economic theory, including the total economic value framework. Finally, all the data collected from the previous steps are used as inputs for a social cost-benefit analysis that produces a result and indicates if the implementation of the platform design specified is feasible or not. A case study is presented and discussed in the light of this assessment tool.

Chapter 2 continues the focus on the implementation of a blue growth strategy but now the target is located at the Northern Mozambique Channel. The Northern Mozambique Channel (NMC) is located in East Africa and covers parts of the Exclusive Economic Zones of Comoros, France, Madagascar, Mozambique and Tanzania, covering an area of some 450000 square kilometres. The coastal population of the NMC is currently 10 million and is largely dependent on its healthy and productive ecosystems through fishing, coastal agriculture, tourism and other activities. The predicted economic and population boom in the region for the next two to three decades will bring increasing economic and social needs of the populations living in the channel. In addition, this area is characterized by globally significant energy reserves, including offshore oil and gas. In this context, there is a significant risk for unsustainable exploitation practices of oil and gas to dominate, delivering a future where the ecosystem that supports livelihoods is degraded and wealth is not shared equitably. Exploring the use of the emerging multidisciplinary methods for the economic valuation of the wide range of marine and coastal ecosystem services provided in this region, this chapter makes a reflection on the role and contribution of these assets towards a blue economy in the region. In this way it reflects on how we might avoid the development errors of the twentieth century in many mineral- and energy-rich developing economies in Africa. Delivering on a blue economic strategy therefore poses significant opportunities but also challenges for the countries of the NMC. This chapter explores the use of a spatially explicit tool to quantify the role of marine natural capital as a contributing factor for integrated ocean governance of the NMC. Maps with information on selected marine and coastal ecosystem services, and underlying assessment tools, are made available to regional institutions such as the Nairobi Convention and Indian Ocean Commission, economic and sectoral bodies such as the Southern Africa Development Community, the Common Market for Eastern and Southern Africa and several regional fishery management organizations. This chapter constitutes a significant informational block in building a regional approach to ocean governance. 


\section{Handbook on the economics and management of sustainable oceans}

Chapter 3 introduces and discusses the rationale behind the need to 'value' the economic benefits of ocean and coastal systems. It provides an overview of the diversity of value frameworks and narratives, and describes the importance of social dynamics and the application of innovative social technologies in enabling change towards sustainable oceans management. In this context, the chapter provides a compelling case that highlights the need to mainstream the value of ocean ecosystem services into human development and economic policies at various scales of decision-making (local, regional, national and global). Finally, it provides insights into improved ways to maintain and enhance ecological qualities, environmental health and social well-being in the context of ocean ecosystems.

Chapter 4 extends the application of multidisciplinary methods to the aquaculture sector, in particular to the aquaculture sector of the Mediterranean Sea and the Black Sea. In these two seas there are many success stories demonstrating the contribution of both traditional and modern aquaculture activities in providing ecosystem services in the form of habitat restoration, carbon friendly and energy efficient aquaculture, biodiversity conservation and respect for the environment by the adoption of better management practices. This chapter presents and discusses some of these success stories. Finally, it identifies the key elements, and underlying methodological architecture, for disentangling and scaling-up the potential economic benefits that an ecosystem-based approach brings to the aquaculture, as well as to the adjunct economic sectors such as coastal tourism. This quantitative information, once recorded, will further contribute in supporting the current policy-momentum for sustainable aquaculture and unlock its potential for blue growth in the region.

Chapter 5 moves the spatial analysis towards the Norwegian coastal waters. In particular, this chapter focuses on the development, and application, of an integrated economic valuation methodology that is made available to the Norwegian Coastal Administration as a decision support tool for evaluating measures to reduce accident risk from maritime transport, including the risk of oil spills. The methodology is based on a damage function approach, which links modelling of the release and dispersion of different types of oil under a range of weather conditions in different locations, with ecological impact assessments in order to develop regional ecological damage scenarios. These scenarios are then passed on to be applied in an integrated valuation economic method that is characterized by the use of survey-based questionnaires, in particular the contingent valuation survey. This is the only method that is able to compute losses of non-use values from a decline in marine ecosystem services. This tool has been calibrated to the specific informational needs of the Norwegian Coastal Administration. These include: (1) reducing the uncertainty in the assessment of ecological impacts from oil spills; (2) improving communication of the scope of marine ecological impacts to questionnaire respondents in terms of size of the affected marine and coastal area, species and services affected, and the duration of the damage; (3) developing a neutral and realistic payment vehicle when asking for willingness to pay for preventive measures; and (4) determining the size of the 'affected population' used to estimate aggregate damage costs. Contingent valuation information can be used to estimate the social benefits of regional measures to avoid oil spills, and can be compared with the associated costs of measures to reduce accident risks in maritime transport.

Chapters 6, 7 and 8 expand the application of innovative multidisciplinary methods 
for valuation of marine and coastal ecosystem services to the Azores, Mauritius, and Japan. Chapter 6 aims at the economic valuation of a selected range of ecosystem services provided by the Condor seamount, Azores and central northeast Atlantic. Once a commercial fishing ground for local fishers, Condor was designated a temporary marine protected area, from June 2010 to December 2017. While activities such as demersal fisheries were banned, tuna fishing was allowed to continue. At the same time, since 2010, other ecosystem services supported by the resource system were expanded, including big game fishing, scientific research and marine ecotourism benefits such as shark diving. Estimates indicate that, currently, the economic importance of non-extractive uses of Condor is about $€ 208000$. In fact, the direct output value of scientific research at Condor in 2014 amounts to $€ 110000$, and the economic value of shark diving activities amounts to $€ 98000$. In addition, in 2014 the economic value of tuna fishing and big game fishing amounted to $€ 310000$, respectively $€ 250000$ and $€ 60000$. All together, we can conclude that this selected range of ecosystem services provided by the Condor seamount is valued at $€ 408000$ which is not statistically different from the mean annual output from demersal fisheries, that is, about $€ 432000$ for the period 1998-2009. These valuation results are very important for policy guidance, supporting the preservation of current marine protected areas. First, the magnitude of the economic benefits generated by the recent governance regime of the Condor seamount, which is based on a marine protected area, is comparable to a former regime, which was based on open access to commercial demersal fisheries. Second, the economic benefits generated by the recent governance regime highlight the importance of these uses as alternative income-generating opportunities for local communities. Finally, the importance of the non-extractive use of these resources presents an increasing trend as a share of the total benefits, in particular shark-diving activities.

Chapter 7 presents the first economic valuation study on ecosystem services in Mauritius. Such a valuation is very important for Mauritius for two reasons. The first is that the national government of Mauritius is now emphasizing, more than ever, the development of the ocean economy. The second is related to the significant impacts of climate change in the coastal region of the country, where adaptation projects will involve ecosystem-based approaches, and subsequently the intensive use of multidisciplinary methods for valuing marine and coastal ecosystem services, making this information available for cost-benefit analysis. This study is based on the use of a contingent valuation survey. It focuses on the valuation of the implementation of a government plan to improve the coastal and marine ecosystem of Baie du Tombeau-Pointe aux Sable. The study uses data collected jointly with the Western Indian Ocean Marine Highway Development and Coastal and Marine Contamination Prevention Project in Mauritius. Results show that the population of Mauritius is willing to pay (WTP) a significant amount for the conservation of the marine and costal ecosystem in Mauritius. According to the estimations, the economic benefits for Mauritius of this conservation plan amount to Rs 184 million (US\$ 5.3 million) annually. Benefits are higher for those who visit the study, since the econometric analysis concludes that reported economic values rise with the frequency of visiting the study area. It is also observed that the reported economic values differ according to rural and urban respondents, with a higher mean value for the urban population than for the rural population. The econometric results also indicate that the reported economic values increase with income and education level, but decrease with age. Finally, attitude towards ecosystem conservation is also a predictor of survey responses, with a 
higher mean economic value associated with respondents who believe they are responsible for taking action to protect the ecosystem. In this context, the informational setting of this study can be used as the baseline to compare the benefits of alternative management plans, including incentive-based instruments such as payment for ecosystem services or spatial protected areas. Reported economic values can also assist in quantifying no-action scenarios of climate change impacts as well as the benefits of adaptation projects. It is worth noting that international donor agencies, and international development banks, are increasingly advocating the use of cost-benefit analysis, especially in the context of climate change adaptation projects in coastal regions. This leads to the most important application of the results of this study, which is policy evaluation and cost-benefit analysis. Mauritius is currently developing new clusters which would spearhead economic activities in its maritime zone. These economic valuation studies such as that presented in this chapter are in high demand in Mauritius.

Chapter 8 concludes Part I by presenting a study of the preferences for marine conservation areas to protect coral reefs in Okinawa, Japan. The marine environment of Okinawa, which consists of a large number of coral reefs, provides many ecosystem services, such as recreational opportunities, coastal protection, and habitat for fish and other marine species. The environmental, economic and social well-being of Okinawa depends on the marine environment's ability to provide a full range of these services. However, the Okinawan marine ecosystem faces a number of threats owing to climate change and human activity. A potential solution discussed among local stakeholders indicates the necessity of expanding the existing marine protected area (MPA) network. This study explores the use of a multidisciplinary, survey-based method for assessing the preferences for establishing such an MPA. Two groups of stakeholders are identified: residents of Okinawa and tourists to the prefecture. Estimation results show that both groups support the introduction of an MPA in Okinawa to protect coral reefs. Tourists, however, have a stronger preference, and therefore report a higher economic value, for an MPA that privileges the zoning of protection of marine biodiversity. Residents, in turn, present a higher economic value for an MPA that privileges the zoning of recreational fish areas. This information plays a crucial part in local maritime spatial planning; identifying clearly who wins and loses across alternative management regimes, which in turn is a fundamental block in consensus building.

The chapters in Part I show the need to integrate contributions from different disciplines in creating a solid method able to address the valuation of the complex set of ecosystem services provided by the oceans, including marine and coastal ecosystems.

Today, more than ever, one of the most in-demand services from international professionals working in the field of economic valuation of ecosystem services is to embed and interface their technical work and reported economic values into management and policy. That is, professionals are asked to design, test and apply the economic valuation studies that directly address specific management questions, informing policy-makers of the costs and benefits of policy (in-)action. In this context, Part II, 'The testimony of economic valuation studies in ocean management', presents recent empirical valuation work that addresses this aspect, tailoring the valuation conventional tool box to the specific policy needs - as we are not in front of a 'one size fits all' setup. This part starts with Chapter 9, which focuses on the evidence of economic valuation in the management of the Mesoamerican Reef. This reef extends over 1000 kilometres from the northern tip of the Yucatan Peninsula, Mexico, south to the Bay Islands off the north coast of 
Honduras, including Guatemala's Caribbean coast and all of Belize. The area includes the largest barrier reef in the western hemisphere. Recently, the World Resources Institute estimated that services from the Belize reef and mangroves, alone, were valued between US\$325 million and US\$559 million per year, notably in supporting local livelihoods (tourism and fishing) and coastal protection. The chapter reports the work of the Healthy Reefs Initiative (HRI) over the past ten years in developing a common vision and definition of reef health, including quantitatively defined indicators, which are collaboratively monitored and jointly reported. The HRI, and its 60 plus partners in the Mesoamerican region, meet annually to collectively review the reef health data and management recommendations. These are presented on 'Report Cards'. This collaborative process and the user-friendly tools it generates provide decision-makers with the most comprehensive, yet easily understandable, scientific data available. Over the past ten years the HRI has published four Report Cards on the health of the Mesoamerican Reef. This work has contributed to measurable actions that have improved the health and management of the reef, including the establishment of new marine protected areas and fully protected zones, the protection of key herbivores and the strengthening of sewage effluent standards, to name a few. The reports also enable the evaluation of management actions in a regional scale and put the concept of 'adaptive reef management' into practice. In this context, the chapter addresses and discusses 'Report Cards' as a scientifically credible, respected and standardized method to monitor reef health in the region, providing examples of how the process has promoted improved management and environmental decision-making. Furthermore, the chapter discusses the potential of the reports in guiding decision-makers in resource management policies, aimed at protecting both the reef and the livelihoods of communities depending on healthy reefs. Finally, the chapter addresses the contribution of this tool to produce routine ecosystem and management evaluations that are regionally comparable in the Caribbean, catalysing swifter and more comprehensive reef management actions and a broader public understanding and appreciation for the value of this reef system.

Chapter 10 presents a different tool for the management of human activities in the oceans - the overarching ecosystem-based approach (EBA). This environmental management approach integrates social and ecological concerns in ocean management, engaging multi-sectoral stakeholders, giving priority to cooperation and coordination, and adjusting to changes in the circumstances. The chapter identifies the necessary elements to implement the EBA through adaptive management. Furthermore it addresses the application of the EBA to management of sustainable oceans, and their challenges, providing examples on concrete tools to bring these elements into practice.

Chapters 11, 12, 13 and 14 explore the use of the EBA across different geo-policy settings. Chapter 11 focuses on the impact of high seas closure on food security in lowincome fish-dependent countries. Recent proposals to close the high seas to fishing have indicated that this may be beneficial for the rebuilding of fish biomass, increasing the quantity and improving the distributional equality in global fisheries catch, and increasing the resilience of fish stocks to climate change. How high seas closure will impact food security for the poorest and most fish-dependent countries, however, is not clear. This chapter aims first to identify which countries will be positively and negatively affected by high seas closure. Then, the chapter discusses whether the effect of high seas closure will impact upon locally consumed food fish. Estimation results show that almost 60 per cent 
of the countries in the study would potentially be affected by high seas closure. Overall, high seas closure may benefit local fish supply in less than half the assessed countries. Finally, the chapter concludes by informing us that low-income countries may stand to benefit the most from high seas closure in terms of having the largest proportion of countries projected to experience catch gains. However, it is also important to bear in mind that countries projected to experience catch gains, but where straddling taxa are not used domestically, can still attain food security benefits indirectly through economic and household income effects arising from an increase in fisheries output.

Chapter 12 proceeds with the testimony of economic valuation studies in ocean management, in particular in the context of the Mediterranean Sea. In the Mediterranean Sea jellyfish outbreaks are part of anthropogenic alterations of the marine ecosystems and have been documented as health hazards, fisheries predators and threats to tourism. Their impacts on human welfare, however, have been poorly quantified. This chapter addresses this gap and presents the main findings of impacts on recreation and beach recreationists' welfare in two specific areas of the Mediterranean Sea: the cities of Barcelona and Tel Aviv. Two international teams with overlapping researchers conducted two valuation assessments simultaneously in the summer of 2013 in both areas. According to estimation results, jellyfish outbreaks in Israel are responsible for a reduction of the number of seaside visits of between 3 per cent and 10.5 per cent, which corresponds to a total welfare loss of between $€ 1.8$ million and $€ 6.2$ million, per season. The Israeli study suggests that international visitors and long-distance domestic visitors are the categories of recreationists that are most negatively affected by the outbreaks. In Barcelona, estimation results show that aggregated well-being gains associated with a reduction of jellyfish blooms in this area would be around $€ 422.60$ million, corresponding to approximately 11.95 per cent of the tourism expenditure of the Catalan population. Contrary to the Israeli study, the Catalonia study suggests that domestic visitors, mainly from the Barcelona metropolitan area, are the category of recreationists that are most negatively affected by the outbreaks. From a management perspective these results call for policy action. However, it seems apparent that damage to Mediterranean ecosystems will be difficult to reverse and this may take decades even with concerted efforts. So mitigation becomes important. One important mitigation tool is disseminating information about jellyfish conditions of the beaches. Subsequently, a worldwide premier iPhone application was developed. This app is called iMedJelly ${ }^{\odot}$ and is currently in full operation during the summer period along the entire coastline of Catalonia. It provides daily, near real-time information about the presence (or not) of jellyfish on the selected beach. Such public information can substantially reduce monetary losses associated with jellyfish outbreaks as beach recreationists are now able to make informed decisions, minimizing the occurrence of involuntary contact with jellyfish.

Chapter 13 analyses the story of the successful application of a co-management fishing regime for Sergestid shrimp in Suruga Bay on the central Pacific coast of Honshu, Japan. Sergestid shrimp, called Sakura-ebi locally, is a shrimp of 40-50 millimetres body length occurring abundantly in Suruga Bay. In Japan, fisheries' rights to a sea area under the jurisdiction of the Fishery Cooperative Association (FCA) are the property of each association, which then allocates to individual fishermen the rights to fish certain stocks or resources. Each association establishes its own rules and regulations to control the operation of the various types of fisheries. The society of Sergestid shrimp fishermen in Suruga 
Bay initiated a unique operating system in 1968, following the need for improved resource management. The established system, which is still operating, requires all members of the society to share equally the sold value of the total landings, regardless of the amount of the harvest of each member. In this context, this chapter provides a comprehensive analysis of the equitable share system in Suruga Bay and how the system has contributed to establishing a sustainable management of the Sergestid shrimps. Secondly, Chapter 13 analyses how an economic approach, which addresses both costs and benefits, can facilitate similar systems of equitable share to be adopted by other FCAs in Japan where other species are harvested. The chapter concludes with some lessons of the equitable share system applicable to other areas of oceans to create a sustainable marine resource management.

Chapter 14 provides a review of the socio-economic impacts of marine litter, including the costs of policy inaction on tourism, fishing and shipping. The chapter reviews studies that measure how polluted beaches reduce the recreational use and aesthetic value of areas and can discourage visitors from certain beaches, leading to a loss of revenues for the tourism sector. For example, beach litter on the Skagerrak coast of Bohuslan (Sweden) has been estimated to decrease tourism by between 1-5 per cent, leading to an estimated annual loss of approximately US\$24 million and 150 person-years of work to the local community, with local clean-up efforts costing approximately US\$1.5 million per year. The chapter addresses how marine litter can lead to the loss of output or loss of value in the sales of certain types of seafood and fish. The loss of marketable lobster owing to mortality caused by abandoned or lost fishing gear is estimated to lead to a global loss of US\$250 million per year. In addition, the chapter focuses on the costs to the shipping sector, which include accidental losses of cargo, collision with items of marine litter, fines following negligence or illegal dumping and indirect costs from interruption of service. In 2008, 286 rescues of vessels with fouled propellers in UK waters were carried out at a cost of between US\$1.12 million and US\$2.96 million. While the information on the costs of policy action is still patchy, the existing evidence base suggests that the costs of inaction are likely to outweigh the costs of taking action to address marine litter, and that a hierarchy that prioritizes avoidance, minimization and recycling in preference to end-of-pipe clean up could usefully be followed as a general rule. Finally, the chapter reviews a range of initiatives under way to understand the scale of the problems and the types of solutions, including UNEP's Global Programme of Action for the Protection of the Marine Environment from Land-based Activities (GPA) and the Global Partnership on Marine Litter (GPML). It will be essential to help create an awareness of how each stakeholder group - public sector, private sector, individuals and communities - can contribute to those solutions.

Chapter 15 looks at two widely used economic instruments - taxes and subsidies and how these affect sustainable management of oceans in general, and fisheries in particular. The chapter reviews statistics that show that taxes from fishing and other maritime activities are often much smaller than capacity-enhancing government subsidies. In many regions, fisheries and other ocean-based extractive activities would be unprofitable were it not for subsidies. The contrast between the two fiscal instruments is so great that they could be described as 'the minnow' (taxes) and 'the whale' (subsidies). Despite more than ten years of negotiations, global attempts to reduce subsidies has had little success. Fishing subsidies remained high, at over US\$35 billion in 2013, leading to 
over-exploitation of ocean resources. Not all is doom and gloom, however. The picture is more positive for fishery licence fees. A number of countries have increased fees for fishing licences. For example, in the Pacific, fees for tuna increased fourfold to US\$230 million in 2012, although licence fees were still dwarfed by subsidies. It is important, however, to distinguish between harmful subsidies - which increase fishing and other extractive capacity - and beneficial or 'good' subsidies that could help sustainable management of oceanic resources, and in some instances where they have made positive contributions to the overall well-being of fisher communities and poverty alleviation. There has been limited progress in moving away from harmful subsidies towards beneficial subsidies such as incentives for monitoring and enforcement. The chapter concludes with the observation that international frameworks to tackle the wide use of subsidies particularly by high-income countries need to be strengthened. In addition, and at national level, governments should have clear targets to curb and eventually eliminate harmful subsidies. This is now more timely than ever, as the Open Working Group proposal for Sustainable Development Goals calls upon countries 'by 2020, (to) prohibit certain forms of fisheries subsidies which contribute to overcapacity and overfishing, eliminate subsidies that contribute to illegal, unreported and unregulated fishing and refrain from introducing new such subsidies'.

Chapter 16 presents a first attempt to review and analyse potential adaptation strategies and economic policies to cope with ocean acidification. Ocean acidification is a naturally occurring chemical process driven primarily by increased concentrations of atmospheric carbon dioxide $\left(\mathrm{CO}_{2}\right)$. It affects a range of physiological processes including behaviour, growth rates and reproduction in many species. Both the exhibited and potential socioeconomic impacts of ocean acidification are substantial, with the fisheries and aquaculture, coral reef- and marine-based tourism, coastal protection and marine biotechnology sectors all threatened. The first clear message of this chapter is that there are win-win options that need to be exploited. In particular any kind of action that improves marine ecosystem health, resilience or biodiversity could delay and reduce adverse effects of ocean acidification. This includes the implementation of more sustainable fishing practices as well as reducing pollution from agricultural activity. However, the detrimental effects of ocean acidification and climate change on certain habitats in vulnerable regions will prevent MPAs from easily being effective in improving species resilience to environmental change. Marine protected areas could have a type of insurance role if they are placed in locations not particularly vulnerable to ocean acidification and climate change. Second, there are also ocean acidification-specific adaptation options. Many of these (for example, developing new practices in aquaculture or improving coastal protection against storm surges and coastal erosion) turn out to be particularly costly. A third message is that the majority of implementable adaptation strategies have a medium- to long-term effectiveness. Thus they require careful and anticipatory planning to enjoy their benefits reasonably soon and especially to enable them to tackle the problems when they are still manageable. A fourth and final message is that adaptation cannot solve everything. The best coping strategy is reducing ocean acidification by strongly intervening using effective mitigation policies and actions - see also Chapter 19.

Chapter 17 closes Part II by presenting and discussing a set of recommendations to reduce marine plastic pollution. Many initiatives have evolved at local, national, regional and global levels, showing that sustainable solutions for reducing marine plastic pollution 
need to encompass a mix of voluntary and legally binding exercises, and to involve different stakeholders from the plastic and waste management sectors, tourism and fishing industries, the research community, non-governmental organizations, local authorities and national governments. Concerning ocean-based sources, efforts should be made to reduce (in-)voluntary discharge of waste from boats. Fishing nets which are being frequently lost or discarded because of their relative low cost could be tagged to find them when they are lost or discarded. These can be returned to their owners with a fine; at the same time a national deposit/refund scheme should be put in place to reward people for not throwing away fishing nets and encourage collecting discarded fishing gear. In parallel, environmental and education campaigns about plastic pollution, organized at the national or international levels but targeted at specific groups or populations, can be used to raise public awareness and foster a sense of individual responsibility for the end consumer; for instance, regarding waste management hierarchy and the principles of reduction, reuse and recycling (the $3 \mathrm{Rs}$ ). Concerning consumer products market and especially packaging, the chapter identifies an urgent need to set up more effective ecodesign rules, in order to: (1) facilitate industrial and household waste plastic collection, sorting and recycling, (2) incorporate the relatively low quantity and quality of marine plastic gathered by municipal and volunteer cleaning programmes into local solid waste management plans and (3) develop recycling industries and non-recycled plastics-to-fuel technologies (for example, pyrolysis) which need to be equipped with pollution control and adapted to the conditions of the country. In this context, the chapter offers new perspectives for a sustainable development economy, especially regarding waste management and circular economy issues on a regional scale. On a global scale, the adverse impacts of marine plastic pollution highlight the worldwide need to better understand and evaluate the economic value of marine ecosystems; and to substantially improve the management of critical marine resources in a long-term perspective, under population growth and climate change scenarios. In 2015, the political leaders from the forty-first G7 summit in Germany committed to priority actions and solutions to combat marine litter (in particular plastic) by stressing the need to address land- and sea-based sources, removal actions, as well as education, research and outreach.

Part III of the book builds on the chapters presented and addresses the role of science to policy interface in the context of ocean governance. As we have noted, the governance of oceans is fragmented by sector and discipline (fishing, shipping, offshore oil and gas, offshore renewable energy, and so on), as if we were managing separate entities. Also, until very recently, marine science was based on country-driven projects as if the scientific problems were intellectually different or geographically disconnected. This fragmentation can be seen in the proliferation of organizations (governmental and non-governmental) coping with different aspects of the uses of the marine environment, resources and governance. On the other hand, the drivers for ocean scientific research are connected to the sustainable use of the oceans and to understanding how to achieve mitigation and adaptation to climate change. In that sense, the main ocean-related scientific problems of our time are interdisciplinary, involving natural and social sciences, and they need to be addressed on a global scale through extensive international cooperation. To influence and shape action, we must strengthen the interface between policy and science. The ability to make our science understandable to those who make decisions about our future is critical. Several international instruments and science-policy interfaces have 
been created; for example, the Intergovernmental Panel on Climate Change (IPCC) and the UN World Oceans Assessment, Intergovernmental Science-Policy Platform on Biodiversity and Ecosystem Services (IPBES), and these processes must ensure that updated and accurate science is appropriately reflected in high-level policy discussions; for example, the Convention for the Protection of the Marine Environment of the North-East Atlantic (OSPAR), Conferences of the Parties of the Convention of Biological Diversity and the United Nations Framework Convention on Climate Change (UNFCCC). The success of these international forums to improve the governance for better ocean management together with commitments to reduce the human impact on the ocean and marine ecosystems depends heavily on the decision of governments and states; and multilateral organizations such as the UN agencies play a decisive role in making this governance a reality.

In this context, Chapter 18 reviews the role of the UN system in facilitating better governance for ocean research and management for a safer, more equitable, cleaner, and more prosperous ocean for all.

Chapter 19 reviews the scientific community's understanding of ocean acidification and considers the extent to which it has factored in multilateral dialogue on ocean governance. As contemporary ocean acidification and climate change share a common root - the anthropogenic emissions of $\mathrm{CO}_{2}-$ it is tempting to package ocean acidification governance measures as a subset or element of climate change governance measures. This chapter calls attention to the fact that ocean acidification is not the offspring of climate change, but its sibling. They affect each other, but each could exist without the other. Ocean acidification has only recently been dissociated from the suite of climate change manifestations and is discussed as a parallel and synergistic phenomenon. The chapter observes that the consequences of ocean acidification will fall asymmetrically upon ecosystems and communities. Specific (local) vulnerabilities, adaptation capacities and mitigation strategies will play an essential role in the distribution of ocean acidification socio-economic impacts. The chapter concludes by stressing the urgent need to escalate research from individual species to biological community and ecosystem levels, as inter-species dynamics and other environmental stressors (for example, hypoxia, temperature and nutrients) play an essential role, complementary to $\mathrm{pH}$ levels, in biological processes in marine organisms. Similarly, there are still many gaps in the assessment of potential socio-economic impacts of ocean acidification. Currently we are unable to make long-term, reliable quantitative predictions on the abilities of ecosystems to acclimate and adapt to ocean acidification, and therefore accurately predict the socio-economic effects on humans. The fundamental premise of the chapter is that good governance of the ocean requires a normative and institutional infrastructure that consistently observes, addresses or adapts to long-term trends, while simultaneously and efficiently responding to short-term perturbations in a manner that ensures development goals can be fully realized. Failure to contextualize short-term events - be they bio-physical, economic or social - against the long-term trend of ocean acidification will significantly increase the risk that economic, regulatory or social policies affecting the ocean will fall short of their intended outcome.

Chapter 20 focuses on the role of private governance of oceans resources. Industry and civil society actors are becoming increasingly active in ocean governance. What does this movement look like, how has it emerged and what are its consequences? This chapter provides an overview of the main private ocean governance initiatives, and discusses how 
these initiatives interact with the more traditional forms of state governance. The chapter addresses the examples of seafood certification, traceability schemes, and entrepreneurial marine protected areas. It concludes that private governance can potentially complement state governance, particularly where public institutions are weak. However, at the same time private governance initiatives alone cannot attain policy objectives in what is essentially an open-access or common-property resource.

Chapter 21 presents the Global Environment Facility (GEF) perspective on ocean governance. As the largest financial institution with the ability and experience to confront the challenges facing shared marine and coastal ecosystems, the GEF is committed to ensuring the long-term sustainability of the oceans. Since its establishment in 1991, the GEF, through its International Waters (IW) focal area, has allocated a total of $\$ 1.14$ billion in project grants to transboundary, marine projects. International Waters marine projects have addressed the breadth of threats and issues facing ocean governance ranging from fisheries to toxic substances, with the majority of funds allocated to addressing land-based sources of pollution and building large marine ecosystems (LMEs). As discussed in this chapter, GEF initiatives have adopted two critical approaches for successful ocean governance: building transboundary partnerships to manage shared ocean resources and taking on-the-ground actions tied to sustainable development. First, the GEF supports countries to collectively manage coastal and marine ecosystems in order to share the benefits from them. This transboundary approach is unique in bringing together countries to identify threats, problems and issues through a structured, common fact-finding dialogue between governments, academia, civil society and the private sector, termed transboundary diagnostic analyses (TDA). Such a unifying process is essential to then agree on a shared vision and investment plans towards limiting stress on the shared marine resources, termed strategic action programmes (SAPs). For example, in the Benguela Current Large Marine Ecosystem, the nations of South Africa, Angola and Namibia conducted the TDA/SAP process, building upon which they established the Benguela Current Commission and adopted the Benguela Current Convention. Similarly, in the Yellow Sea LME, the Republic of Korea and China conducted the TDA/SAP process which resulted in commitments to reduce fishing fleets by 30 per cent. These commitments are now under implementation and unique in bringing these two nations toward shared ocean governance. These multinational political commitments are complemented by the second GEF approach, which is supporting national and locallevel actions to reduce land-based sources of pollution, build sustainable fisheries, and minimize habitat degradation with ties to sustainable development. In terms of reducing pollution, wastewater projects in the Caribbean and East Asia introduced progressive, yet affordable, practical technologies, catalysed institutional reforms, and throughout raised political awareness regarding the social and economic importance of wastewater management. The result was improved water quality to benefit the coastal ecosystems as well as recreational and tourism users. Sustainable fisheries initiatives in the Pacific, West Africa, Latin America and the Caribbean and South Asia have established standard stock assessment systems, operationalized satellite-based monitoring, control and surveillance devices, improved inland processing and post-harvest handling, established fisheries comanagement schemes and strengthened regulatory frameworks, which have contributed to improved food security for the coastal communities. With an emphasis on integrated approaches, this chapter concludes by stating that future GEF projects are expected to 
better incorporate relevant issues, such as climate change and land degradation, as well as work across the watershed from source to sea. At the same time, the GEF is increasingly emphasizing private sector engagement, which ensures the stakeholders who have the most to benefit and lose economically play an active role in providing for the long-term sustainability of oceans.

Chapter 22 describes the recent developments addressed to the regional fisheries management organizations (RFMOs) after the adoption of 'the future we want' at the Rio+20 Conference, the United Nations Conference on Sustainable Development. The message of the Rio+20 Conference to the RFMOs was a call to be more transparent and accountable, supporting more participatory decision-making processes. In particular, the chapter focuses on the role of the General Fisheries Commission for the Mediterranean of the FAO (GFCM) and how this RFMO responded to the message of Rio+20. Clear-cut divides between human activities, such as fishing, and the preservation of marine environment are not possible anymore. The chapter presents and describes the steps that led to the alignment of GFCM's institutional and legal framework with the objectives proposed at Rio+20 Conference. Ultimately, the GFCM Agreement was amended in 2014, following an internal process of approval by FAO governing bodies. The chapter concludes that the GFCM Agreement is now fully consistent with the management of fisheries envisaged by Rio+20 and, in this way, is contributing to the achievement of sustainable development in the Mediterranean and the Black Sea.

Chapter 23 moves from the Mediterranean and Black Seas to focus on governance on the West African coast. West African countries are well known for weak governance and over-exploitation of fisheries. Illegal fishing for example, one of the main causes of fisheries collapses, has been spreading fast in West Africa during recent decades and has been directly linked to weak governance and a poor decision-making framework. This chapter analyses different paths through which governance impacts fisheries management, policy and conservation priorities through the example of Senegal as a case study. It notes that small-scale fisheries in Senegal are governed by pre-existing traditional systems which, although in decline, still play a major role. Despite the encouraging signs of a shift from a top-down centralized approach to co-management, small-scale fishing communities in Senegal still describe co-management initiatives and governance as 'bad' because of the formal non-inclusion of small-scale artisanal communities, which have retained their status of mere 'observers'. The case of Senegal is not unique in the region and other examples illustrate how to effectively shift away from the traditional centralized approach to a scheme that is more adapted to the needs of region. The chapter concludes that additional work needs to be done in Senegal and, by extension, other countries within the region, in terms of implementation, inclusion of traditional knowledge and traditional management institutions. Only in this way is it possible to enhance and strengthen the rapidly developing co-management initiatives for a better governance model.

Chapter 24 presents the Portuguese National Ocean Strategy 2013-2020. The chapter offers a new development model of ocean and coastal areas that may support Portugal to meet the challenges for the promotion, growth and competitiveness of the blue economy, in particular, the important changes to the political and strategic framework at both European and worldwide levels. In addition, it identifies the areas of intervention and presents the action plan, which includes the programmes to be run and developed, 
in order to achieve specific objectives and produce the desired effects, being subject to proper monitoring, evaluation, review and update mechanisms. In particular, the chapter presents the Mar-Portugal Plan, an action plan mainly aimed at the economic, social and environmental valorization of the national maritime space through the implementation of sectorial and cross-sectorial projects, as well as the already existing national strategic plans or those in preparation. The chapter concludes by discussing the challenges posed in the implementation of such a national ocean strategy, including the sort of tailoring of the water space and the implementation of maritime spatial planning, the achievement of the good environmental status of the marine and coastal waters, and the way informed decisions are supported making best use of scientific knowledge about the ocean.

Chapter 25 addresses regional governance for the protection of the ocean environment and its biodiversity. Regional oceans' governance has been taking place mainly through: (1) Regional Seas programmes, many of them supported or coordinated by the United Nations Environment Programme; (2) regional fishery bodies, some established under the framework of the United Nations Food and Agriculture Organization; and (3) large marine ecosystem mechanisms, including projects supported by the Global Environment Facility - see also Chapter 21. Although based on a similar geographical approach, these regional mechanisms raise concerns relating to their coordination and efficiency, and possibly overlap in what they aim to achieve. This chapter presents a brief but thorough review of existing regional ocean governance mechanisms. The review is intended to assist states that participate in such mechanisms, as well as those that consider participating, by clarifying the key distinctions between the mandates of these mechanisms, and highlighting the successes and challenges of existing mechanisms and cooperation between them. Furthermore, the chapter identifies options for strengthening existing mechanisms and cooperation between them, as well as for the creation of new regional ocean governance mechanisms, with particular reference to the ecosystem approach. Finally, this chapter synthesizes key issues as well as findings from the review for non-specialists, with particular emphasis on practical recommendations.

Chapter 26 discusses the importance of an ocean-literate citizenry, and how ocean literacy relates to more established concepts such as scientific literacy and environmental literacy. All aspects of our life (for example, cultural, historical, biological and economic) are deeply rooted in oceans, no matter where we live. However, education and communication have a key role to play in fostering our appreciation of the importance of oceans, our understanding of our own responsibility in their destruction and our awareness of the relevance of their protection. Therefore, increased marine environmental awareness constitutes a real challenge as many features of oceans are difficult to experience because they are too small, too big or too abstract. One example is marine plastic pollution. Thanks to successful communication campaigns, there is a recent strong public, policy and scientific interest in marine plastic pollution. It was recently estimated that more than 5 trillion plastic pieces weighing over 250000 tons are afloat at sea with a range of negative impacts for marine organisms and ecosystems. Communicating about plastic pollution is relatively easy. It is a visual threat (for example, the Great Pacific garbage patch), every citizen can relate to plastic and it has negative consequences on charismatic species such as turtles, whales and birds. The ultimate solution to the problem of ocean plastics is obvious: a significant reduction of plastic use limiting the 
amount making its way into the ocean. Finally, the chapter concludes that it is also critical to promote strategic investments in research at the interface of natural and social sciences, policy, education and communication to better understand how we can implement the needed large-scale collective actions. For example, inter-disciplinary research aiming at developing a general, empirically founded, theory about large-scale collective action should be a priority to develop adequate policy measures facilitating large-scale collective action.

Finally, Chapter 27 highlights the successes of the Global Programme of Action for the Protection of the Marine Environment from Land-based Activities (GPA), and its global activities in improving sustainable management of oceans. In November 1995, over 108 governments laid down 'their commitment to protect and preserve the marine environment from the impacts of land-based activities ... Setting as their common goal sustained and effective action to deal with all land-based impacts upon the marine environment, specifically those resulting from sewage, persistent organic pollutants, radioactive substances, heavy metals, oils (hydrocarbons), nutrients, sediment mobilization, litter, and physical alteration and destruction of habitat.' The commitment was made under the auspices of the GPA and the associated 1995 Washington Declaration. This has been renewed through the Montreal and Beijing declarations in 2001 and 2006, respectively, and finally through the Manila Declaration in 2012. Governments decided at the Third Intergovernmental Review of the GPA (from which resulted the Manila Declaration), that the Coordination Office should focus its future work on nutrients, litter and wastewater as the three priority source categories for the GPA, using global multi-stakeholder partnerships. In parallel, some of the 18 Regional Seas Conventions and Action Plans (RSCAPs) have negotiated legally binding protocols on land-based activities and sources of marine pollution. The chapter stresses that the current focus of the GPA is therefore on strengthening three global partnerships on nutrient management, marine litter and wastewater. In this context, this chapter addresses and encourages governments and regional organizations to prepare and implement comprehensive, continuing and adaptive action plans to protect the oceans and marine environment. Actions have been taken at municipal, national, regional and global levels, recognizing the effects on food security, poverty alleviation and ecosystem health, as well as the resulting economic and social benefits. It also identifies lessons learnt from implementing the GPA, over the past 20 years, in improving management of land-based activities which impact on our oceans.

\section{THE WAY FORWARD}

The ever-growing human and farm animal populations demand increased resources from the ocean in the form of fish protein, minerals, hydrocarbons and renewable energy from wind, tide, current and wave. Technology has become available that enables resource exploitation by private industry or sovereign states of the deepest and coldest parts of the ocean. This new paradigm is rapidly generating new science and legislation to underpin the associated marine spatial planning, provision of protected areas and sensible governance of the marine estate. We close this introduction by drawing out some key messages. 


\section{Governance Must Include an Ecosystem Approach}

A number of chapters in the book show how this approach can be made operational in support of ocean governance. Chapter 10 illustrates how ecosystem approach principles can be operationalized. One example of ecosystem-based management is applied in Chapter 6 on how the Condor seamount supports multiple human uses at the same time as facing multiple pressures and impacts. The finding of this study demonstrates that the seamount is capable of supporting a wide range of uses, both extractive and nonextractive, generating distinct economic outputs, if integrated and sustainably managed. Most ecosystems that sustain our living conditions on earth and our natural capital are still being lost at alarming and possibly irreversible rates. As discussed in Chapter 3, it is by understanding the value of our marine ecosystems, and the need for (an) inclusive approach(es) to valuation of ecosystems and their services, that we can arrive at better decisions in making policies that affect millions of people around the world. Making the right decision at the policy level makes the difference between a poor fishing community being able to feed their families and sustain their livelihoods or not. There is the need to identify multidimensional value systems and accurately define them in order to improve policies, develop legislation and inspire actions related to the ocean at global, regional and national levels.

\section{No Single Bullet}

No single approach will be sufficient to address the complexity of the issues that currently face the world's oceans. Instead, solutions must be multidimensional and integrate all aspects of the socio-ecological system. For example, aquaculture can make a vital contribution to meet the growing demand for animal protein and provide critical jobs in developing countries. Research is needed along with governing systems designed to develop aquaculture practices that not only provide food and livelihoods, but also ensure minimal negative impacts on the environment. In Chapter 24, Ribeiro et al. present the Mar-Portugal Plan, a governance action plan aimed at the economic, social and environmental valuation of the national maritime space, creating the conditions necessary for the growth of the blue economy and environmental and social improvements. They also reveal how current concepts and processes supporting socio-economic monitoring still strongly connect to a merely continental vision of the global economy, missing out two-thirds of the planet's resources and the opportunities they entail for developing a sustainable blue economy and as a foundation for protecting the future of mankind. In this context, tailored economic, social and environmental policy, as well as a special focus for regional policy, is pursued, including a financial and human resources agenda under an orientated institutional coordination that takes into account local conditions.

\section{Patchwork of Governing Bodies}

There is not one focal point within the UN system for the oceans. To date, there are no significant ocean-related roles in over $20 \mathrm{UN}$ bodies including the World Meteorological Organization, the International Seabed Authority, and the Food and Agriculture Organization of the United Nations. This inevitably leads to some confusion over which 
UN agency should take the lead on ocean issues. Changing jurisdiction of the seas might lead to an increasing amount of regional legislation governing ocean areas. It is appropriate to enhance the role of regional seas conventions, regional action plans and regional fisheries management organizations, and recognize the importance of regional coordination, monitoring and follow-up. In this regard the United Nation Environmental Programme plays a strategic role in enhancing cooperation and coordination among regional as well as international organizations that have a mission and role in the governance and management of oceans and their natural resources.

\section{Blue Economy - Solutions for Sustainable Usage of Resources}

The concept of blue economy can help us bring attention to the economic value and the potential for economic growth. However, a blue economy must be based on the principles of sustainable development. The potential for growth in tourism, energy, aquaculture and so on is remarkable if we develop the economies at the limits of the planet's boundaries. The principle of a sustainable blue economy adds an innovative approach, which could include reusing, repairing, refurbishing and recycling existing materials and products. What used to be regarded as 'waste' can be turned into a resource. The aim is to look beyond waste and to close the loop of the circular economy. This is particularly the case with plastic pollution as addressed in Chapters 14 and 17. By forming publicprivate partnerships, different stakeholders (public sector, private sector, individuals and communities) each need to be involved if the tide is to be turned on marine litter. If we apply an innovative management of marine resources the global society should benefit from an economic, an environmental and a social aspect. Governments should be encouraged to develop partnerships with industry and civil society, including sectors such as fisheries, aquaculture and tourism.

\section{The Role of the Private Sector}

It is important for ocean industries to monitor the major international ocean policy and governance processes that are not sector specific, but that will affect business operations in the oceans. These processes are progressing through a variety of intergovernmental arenas with little or no industry involvement. We must ensure that balanced information is put forward and that the business community is informed and constructively engaged in monitoring, analysing and reporting on major ocean policy- and decision-making processes and developments. In general, effective solutions will require a range of stakeholders from the public and private sectors to share responsibilities and rights in using and protecting ocean resources. For example, the public sector may provide the physical marketplace, facilitate community engagement, ensure transparency, inspect goods for safety, detect violations, provide enforcement and compliance, and prosecute violations. The private sector can execute the trade and exchange of goods, while open access to information can create the pricing structure and incentives that inform the market system. Governance must be linked into other processes related to oceans, such as the Convention on Biological Diversity (CBD) and the UN Informal Consultative, the Process on Oceans and Law of the Sea (ICP). Additional processes to consider for monitoring include: the UN Biodiversity in Areas Beyond National Jurisdiction (BBNJ), the UN Regular Process 
for global reporting and assessment of the state of the marine environment (Regular Process), the UN Commission on Sustainable Development (CSD), the International Whaling Commission (IWC) and the Rio+20 Conference. The lack of top-level leadership on ocean affairs is one of the principal reasons for the failure of different efforts to improve coordination and coherence of policy between the various agencies and bodies that have, within the UN system, a mandate related to the oceans. 
Paulo A.L.D. Nunes, Lisa Emelia Svensson, and Anil Markandya - 9781786430724 Downloaded from PubFactory at 04/26/2023 09:42:48AM via free access 